\section{DECLARATION \\ OF THE SEE-ITS PROJECT PARTNERS FOR INCREASED COOPERATION AND DEPLOYMENT OF INTELLIGENT TRANSPORT SYSTEMS IN SOUTH-EAST EUROPE}

"SEE-ITS" is a project funded by the South-East Europe Transnational Cooperation Programme, aiming at developing an institutional and technical framework for the countries in South-East Europe (SEE), in order to harmonize their national ITS specifications with the European policies (the 2010/40/EU Directive and its subsequent Delegated Acts for the deployment of ITS and other related policy documents) and to define the necessary guidelines and recommendations for further development and deployment of ITS in the SEE area.

The project examined the current status of ITS deployment in the SEE countries, including analyses of the strengths and weaknesses of each country as well as the opportunities and threats for the future ITS deployment in SEE. Moreover, new roadmaps for ITS were developed for the first time for eight SEE countries, that can be used as a guide for the next five to fifteen years for the deployment of seamless and efficient ITS applications. The initial frameworks of national ITS architectures in these eight SEE countries, which have also been developed within the framework of the SEE-ITS project, can similarly support the seamless and harmonized deployment in SEE, not only at national, but also at transnational level. This is an innovation not only for SEE countries, but also for EU and can be utilized further for all member states in the future, in order to pave the way for seamless ITS deployment throughout Europe. Furthermore, seven targeted ITS demonstrations within the activities of SEE-ITS and Cost-Benefit analyses and proposals for new business models supporting the increased deployment of ITS in the SEE area were executed in order to assess the benefits and the impacts of harmonized and interoperable ITS deployment.

The SEE-ITS project established also a permanent cooperation framework for ITS activities in SEE through expert groups and stakeholders' panels, as well as through the organization of thematic workshops and conferences in Greece, Hungary, Bulgaria and Romania.

Taking into account the results of SEE-ITS and the fact that:

- South-East Europe is one of the most diverse areas in Europe, including both EU and non-EU member states,

- this diversity is also reflected in various levels of economic, social, infrastructural, technological and administrative - institutional aspects,
- accessibility is considered to be one of the prime requirements for economic development, growth and territorial cohesion, facilitating the movement and interaction of people and the exchange of goods and ideas,

- existing networks in SEE include several main transport corridors and are in most cases heavily fragmented and serve primarily single states and regions,

- in most cases these networks are of inferior quality, with critical and heavily used road infrastructure but without the development of viable alternatives,

- the enhancement and systematic deployment of Intelligent Transport Systems (ITS) is crucial in monitoring and controlling traffic along road transport networks at transnational, regional, and local (urban/periurban) level,

- ITS comprises key tools to support effective transport infrastructure and traffic management and traveller information provision,

- the current status of ITS deployment in SEE is rather fragmented and a lack of an integrated multimodal transport approach that will effectively adopt and take into account the EU ITS (2010/40/ EU) Directive's guidelines and its subsequent Delegated Acts in all SEE countries is observed,

- the results of the SEE-ITS project already significantly contributed in a positive way to the above,

the SEE-ITS project partners:

- underline the importance of increased connectivity and accessibility throughout the South-East Europe area for the benefit of all,

- underline the importance of ITS in the transition towards more efficient, safe and green transport systems,

- underline the importance of increased deployment of ITS in the South-East Europe area for improved mobility of passengers and goods,

- commit to intensify their efforts for increased deployment and innovation for ITS at national and South-East Europe level,

- commit to support harmonized deployment of ITS in the South-East Europe area,

- agree to create collaborative schemes for the promotion of synergies between all ITS stakeholders in the South-East Europe area,

- underline the importance of increased innovation and development through ITS,

- encourage the development of strategies for the wider deployment of ITS in the South-East Europe area,

- commit to contribute to and support such strategies for the wider deployment of ITS in the SouthEast Europe area,

- commit to contribute to the targets and to promote the adaptation of the 2010/40/EC Directive on ITS, 
- underline the importance of interactions with other national and international ITS Associations' bodies,

- underline the importance of increased cooperation between all relevant stakeholders in the SEE area,

- commit to sustain the existing spirit of trust and cooperation and to further exploit cooperation opportunities in the future,

- call for activities that will assist the deployment of ITS towards sustainable mobility for passengers and goods.

Done at Thessaloniki, 31 December 2014

For the SEE-ITS consortium: Dr. Evangelos Mitsakis, Associate Researcher (LP - CERTH-HIT), Andreas Antonopoulos, President (ERDF PP1 - ADEP S.A.), Martin Russ, Managing Director (ERDF PP2 - AustriaTech), Tibor Feller, Head of Department (ERDF PP3 - KKK),
Rumen Mihaylov, Chairman of the board (ERDF PP4 ITS Bulgaria), Mihai Niculescu, Director General (ERDF PP5 - ITS Romania), Robert Rijavec, M.Sc., Senior Lecturer (ERDF PP6 - UL), Ing. Stefano Dondi, Project Manager (ERDF PP7 - ITL), Lajos Szúcs, President (EU ASP2 - ITS Hungary Association), Dr. Angelos Amditis, President (EU ASP1 - ITS Hellas), Eng. Olga Landolfi, Secretary General (20\% ASP1 - TTS Italia), Prof Sadko Mandžuka, Ph.D., Head of ITS Department (10\% PP2 - University of Zagreb) and Erisa Vora, Project Coordinator (10\% PP1 - SHKTQ).

Prof. Sadko Mandžuka, Ph.D. Head of ITS Department Faculty of Transport and Traffic Sciences University of Zagreb 